COPD exacerbations

\section{Aminophylline for COPD exacerbations? Not usually}

\section{G I Town}

\section{Evidence to suggest that aminophylline should not be used in mild to moderate COPD exacerbations}

$\mathrm{T}$ heophylline is one of those medications that has intrigued and possibly confused clinicians and pharmacologists alike since the mid 19th century. Related agents caffeine and theobromine were used in the 1930s as bronchodilators, and theophylline developed an established place in the management of acute airflow obstruction associated with asthma and chronic obstructive pulmonary disease (COPD) during the mid 1900s. ${ }^{1}$

Pharmacologically, theophylline is characterised principally as a phosphodiesterase (PDE) inhibitor. Its main biological action is to block the inactivation of cyclic AMP and cyclic GMP giving rise to bronchodilation, increased ciliary beat frequency, and reduced inflammatory cell numbers in the airways. However, it has been observed that other PDE inhibitors do not exert such effects, which suggests that other activities may be relevant. Theophylline also acts as an adenosine receptor antagonist, which may be relevant to its desirable effects and probably gives rise to a number of the side effects seen with use of this agent including arrhythmias, mental agitation, and diuresis. As well as bronchodilation, theophylline has a number of other potentially useful actions including improved gas exchange, respiratory stimulation, increased diaphragmatic performance, and improved exercise tolerance. ${ }^{1}$

The pharmacokinetics of theophylline are important because of its narrow therapeutic index. In the acute setting most authorities recommend a loading dose in naïve patients followed by an infusion to maintain a serum concentration within the therapeutic range of 55-110 $\mu \mathrm{mol} / \mathrm{l}$. Because of the many factors which can affect theophylline metabolism including a number of potential drug interactions, therapeutic drug monitoring is recommended to avoid serious or even fatal toxicity. In elderly patients cardiac monitoring is advised to check for the emergence of serious tachyarrhythmias. Seizures are another potentially fatal complication. ${ }^{1}$
Current evidence in support of the use of theophylline in acute severe asthma or COPD is weak at best. With regard to COPD, a recent meta-analysis published by Barr and colleagues identified four small clinical trials of oral or intravenous theophylline (aminophylline) suitable for inclusion, comprising a total of 169 subjects. $^{2}$ Summary data showed no benefit in terms of lung function, symptom scores or length of hospital stay, but a significant problem with side effects such as nausea and vomiting together with a non-significant increase in palpitations compared with placebo. They concluded that there was no clinical benefit, and this research informed the statements in both the UK and Australasian management guidelines on the subject that "it should only be used when there is an inadelators" (grade D, NICE guideline) ${ }^{3}$ and "the routine use of aminophylline is not recommended for acute exacerbations" (grade D, Thoracic Society of Australia and New Zealand guideline). ${ }^{4}$

A notable feature of published papers, including the meta-analysis by Barr et $a l^{2}$ is the small sample size of previous adequately powered study is published which more or less clarifies the picture regarding the use of aminophylline in acute exacerbations of COPD. Duffy and co-workers ${ }^{5}$ studied the effects of adding intravenous aminophylline to usual care in subjects admitted to hospital with an acute exacerbation of COPD. Eighty well matched, non-acidotic subjects were randomised in a double blind fashion to receive intravenous aminophylline $0.5 \mathrm{mg} \mathrm{mg} / \mathrm{kg} /$ hour or placebo and were then followed for 5 days. All subjects received nebulised bronchodilator and oral corticosteroids. The study showed no difference in spirometric values between the two groups, and there was no difference in symptom scores or length of hospital stay. The mean theophylline level achieved in the intervention group was $73.4 \mu \mathrm{mol} / \mathrm{l}$ (range 62.9-83.9). A significant proportion of quate response to nebulised bronchodistudies. In this issue of Thorax an the participants receiving active treatment experienced adverse effects including nausea in $46 \%$. In six subjects the drug was stopped due to possible side effects including one subject who experienced a seizure during the second hour of treatment (the drug level was in the therapeutic range at the time of the seizure $(53 \mu \mathrm{mol} / \mathrm{l})$ and the seizure was later attributed on clinical grounds to alcohol withdrawal).

As might be expected, the investigators did not include subjects with very severe exacerbations. Those with a $\mathrm{pH}$ of 7.32 or less were excluded from entry to the study. The subjects on active treatment sustained a small but significant change in gas exchange parameters with a fall in arterial carbon dioxide tension and a small rise in $\mathrm{pH}$ over the initial 2 hours of treatment. This finding would be in keeping with the drug's known positive influence on respiratory drive.

Thus, in considering the generalisablility of the study, aminophylline might still be considered in the management of life threatening episodes of COPD by an experienced doctor in selected cases, together with other measures such as non-invasive ventilation. In such circumstances the benefits of respiratory stimulation and any effect on respiratory muscles may be more important than bronchodilation per se. However, for most clinical situations involving mild to moderate COPD exacerbations, we now have a clear answer to the question whether aminophylline should be used-and it is "no".

Thorax 2005;60:709.

doi: $10.1136 /$ thx.2005.043760

Correspondence to: Professor G I Town, University of Canterbury, Private Bag 4800, Christchurch, New Zealand; ian.town@ canterbury.ac.nz

\section{REFERENCES}

1 ZuWallack AR, ZuWallack R. Theophylline and phosphodiesterase inhibitors in COPD. In: Celli BR, eds. Pharmacotherapy in chronic obstructive pulmonary disease. Lung Biology in Health \& Disease, Volume 182. New York: Marcel Dekker, 2004:239-63.

2 Barr RG, Rowe BH, Camargo Jr CA Methylxanthines for exacerbations of chronic obstructive pulmonary disease: meta-analysis of randomized trials. BMJ 2003;327:643-8.

3 National Institute for Clinical Excellence. National clinical guideline on management of chronic obstructive pulmonary disease in adults in primary and secondary care. Thorax 2004;59(Suppl I): 1-232.

4 McKenzie DK, Frith PA, Burdon J, et al. The COPDX Plan: Australian and New Zealand guidelines for the management of chronic obstructive pulmonary disease 2003. Med J Aust 2003; 178(Suppl):S1-40.

5 Duffy N, Walker P, Diamantea F, et al. Intravenous aminophylline in patients admitted to hospital with non-acidotic exacerbations of chronic obstructive pulmonary disease: a prospective randomised controlled trial. Thorax 2005;60:713-7. 


\section{When should a long acting $\beta$ agonist be added to an inhaled corticosteroid?}

\section{A E Tattersfield}

\section{Evidence suggests that adding a long acting $\beta$ agonist provides more clinical benefit than doubling the dose of an inhaled steroid even for relatively low doses of inhaled corticosteroid}

$M$ eta-analyses are a mixed blessing; they can be helpful and they can be misleading, ${ }^{1-3}$ and meta-analyses of studies in asthma are no exception. ${ }^{4}$ They are misleading when they fail to make clear that the conclusions only pertain to patients fulfilling the inclusion and exclusion criteria for the original studies. To suggest that they either confirm what everyone knows or provide conclusions, from somewhat dubious sources with spurious precision, may be unduly cynical. Nevertheless, it appears to be difficult to identify questions where a meta-analysis is able to provide important new insights into asthma management.

Professor Beasley's group in New Zealand has used meta-analysis in the past to look at the dose-response relation for inhaled budesonide and fluticasone. ${ }^{56}$ The two meta-analyses included all studies that had assessed at least two doses of the inhaled corticosteroid in addition to placebo. The conclusion of the analyses was that, in patients with mild to moderate asthma, $80 \%$ of the maximum benefit occurs with fluticasone $70-170 \mu \mathrm{g} /$ day (depending on the end point studied), and $90 \%$ of the maximum benefit with a dose of 100 $250 \mu \mathrm{g} /$ day. ${ }^{5}$ Similarly, $80 \%$ and $90 \%$ of the maximum benefit from budesonide was seen with doses of 200-400 $\mu \mathrm{g} /$ day and $\quad 300-600 \mu \mathrm{g} /$ day, respectively. Although the mean forced expiratory volume in 1 second $\left(\mathrm{FEV}_{1}\right)$ in these studies was $66 \%$ and $69 \%$ predicted, respectively, suggesting the patients had moderately severe asthma, the patients had to be considered to be safe on placebo since the meta-analyses only included placebo controlled trials. The findings are therefore only generalisable to patients for whom it was considered safe to give no inhaled corticosteroid for several weeks, usually 8 weeks or more. That will include a fair proportion of patients in general practice but fewer in secondary care. The authors recognised this in the conclusion of their second paper, but the caveat is sometimes lost when the data are discussed.

The most recent meta-analysis from the New Zealand group by Masoli and colleagues $^{7}$ published in this issue of Thorax is asking an important question and appears to have circumvented many of the problems outlined above. The authors examine whether, in adults with symptomatic asthma, it is better to add salmeterol to a moderately low dose of inhaled corticosteroid (fluticasone $200 \mu \mathrm{g} /$ day or equivalent) or to increase the dose of inhaled corticosteroid. The analysis included randomised double blind trials and the main outcome measure was the number of subjects withdrawn due to asthma or who had one or more moderate or severe exacerbations. The authors found more withdrawals due to asthma and severe exacerbations in patients taking higher doses of inhaled corticosteroids than in those given salmeterol with the lower dose of inhaled corticosteroid, with odds ratios of 1.58 and 1.35 respectively. The changes in the secondary end points were in the same direction. The differences between groups are not particularly large, but are worthwhile when talking about important end points such as exacerbations.

The strengths of this meta-analysis are that it covers over 4000 patients from 12 studies and the main end point of deteriorating asthma or exacerbations is clinically important and not directly related to bronchodilator activity. The patients had moderately severe asthma with a mean $\mathrm{FEV}_{1}$ of $64 \%$ predicted and did not have to be deemed to be safe with no inhaled corticosteroids. The question is also important since, although there is reasonable agreement that, in general, adding a long acting $\beta$ agonist provides more clinical benefit than doubling the dose of an inhaled steroid, the dose of inhaled steroid at which the addition of a long acting $\beta$ agonist is beneficial has not been clearly determined. ${ }^{8}$ This study suggests that patients taking $200 \mu \mathrm{g}$ fluticasone or $400 \mu \mathrm{g}$ beclometasone or budesonide are likely to fare better if they add salmeterol rather than increasing the dose of inhaled steroid. Quadrupling rather than doubling the dose of inhaled steroid might provide more benefit, as shown in the FACET study with budesonide and formoterol, ${ }^{9}$ but this would involve relatively high doses of inhaled steroid.

Meta-analyses nearly always focus on efficacy rather than the balance of efficacy and adverse effects which is what, of course, a clinician has to take into account before prescribing. Both inhaled corticosteroids and long acting $\beta$ agonists have a good safety record. There may be individual patients, however, where a physician might be influenced by potential adverse effects-patients with osteoporosis or a tendency to develop cardiac dysrhythmias, for example.

Masoli and colleagues limited their analysis to salmeterol because few studies with formoterol fulfilled the inclusion criteria for the meta-analysis. They argue that the effect of formoterol is likely to be similar to that of salmeterol, and this is supported by the findings of the FACET study. ${ }^{9}$ The conclusion that patients who are inadequately controlled on a relatively low dose of inhaled corticosteroid are more likely to benefit from a long acting $\beta$ agonist rather than an increased dose of inhaled corticosteroid should enable firmer advice on this point to be incorporated into guidelines.

Thorax 2005:60:710.

doi: $10.1136 /$ thx.2005.042028

Correspondence to: Professor A E Tattersfield, Division of Respiratory Medicine, Nottingham City Hospital, Hucknall Road, Nottingham NG5 1PB, UK; anne.tattersfield@nottingham.ac.uk

\section{REFERENCES}

1 Egger M, Schneider M, Davey Smith G. Spurious precision? Meta-analysis of observational studies. BMJ 1998;316:140-4

2 LeLorier J, Grégoire G, Benhaddad A, et al. Discrepancies between meta-analyses and subsequent large, randomised, controlled trials. N Engl J Med 1997;337:536-42.

3 Bailar JC III. The promise and problem of meta analysis. N Engl J Med 1997;8:559-60.

4 Jadad AR, Moher R, Browman GP, et al. Systematic reviews and meta-analyses on treatment of asthma: critical evaluation. BMJ 2000;320:537-40

5 Holt S, Suder A, Weatherall M, et al. Doseresponse relation of inhaled fluticasone propionate in adolescents and adults with asthma: meta-analysiss. BMJ 2001;323:253-6.

6 Masoli M, Holt S, Weatherall M, et al. Doseresponse relationship of inhaled budesonide in adult asthma: a meta-analysis. Eur Respir J 2004;23:552-8

7 Masoli M, Weatherall, M, Holt S, et al. Moderate dose inhaled corticosteroids plus salmeterol versus higher doses of inhaled corticosteroids in symptomatic asthma. Thorax 2005;60:730-4

8 British Thoracic Society/Scottish Guidelines Intercollegiate Network. British guideline on the management of asthma. Thorax 2003;58(Suppl I):i1-94.

9 Pauwels RA, Lofdahl C-G, Postma DS, et al. Effect of inhaled formoterol and budesonide on exacerbations of asthma (FACET). N Engl J Med 1997;337:1405-11. 
Glucose, bronchial secretions and MRSA

\section{Glucose, bronchial secretions and MRSA}

\section{J S Brown}

\section{Association of MRSA infection with abnormal glucose levels in respiratory tract secretions}

S rains of Staphylococcus aureus resistant to first line antibiotic therapy (the penicillinase resistant penicillins cloxacillin, flucloxacillin and methicillin), termed methicillin resistant $S$ aureus (MRSA), first appeared in 1961 and are now widespread worldwide. ${ }^{1}$ In the UK MRSA is particularly prevalent, especially on intensive care wards, causing a variety of important nosocomial infections. Infection with MRSA usually requires parenteral therapy with a glycopeptide antibiotic and frequently substantially prolongs the patient's hospital admission. Isolation of carriers places considerable stress on available bed resources and local outbreaks can even result in temporary ward closures. As a consequence, the human and financial burden of MRSA is significant, and this is reflected by the adoption of improved control of hospital acquired infections by a major political party as a major election "pledge".

The paper by Philips et $a l^{2}$ in this issue of Thorax reports a possible association between a positive culture for MRSA from bronchial aspirates from patients in an intensive care ward and abnormally high levels of glucose in the bronchial aspirates (ranging from 2.7 to $4.4 \mathrm{mmol} / \mathrm{l})$. MRSA infection was just over twice as likely in patients with abnormal glucose levels in bronchial aspirates, but the overall incidence of $45 \%$ for isolation of MRSA from the respiratory tract is surprisingly high and may limit the applicability of these results to other hospitals. However, if the association of MRSA with abnormal glucose levels in respiratory secretions is reproducible, it does offer a potential way of identifying patients at risk of MRSA infection. Hyperglycaemia is associated with both an increased severity of pneumonia ${ }^{3}$ and with death from sepsis for patients admitted to intensive care wards, ${ }^{4}$ providing support for a relationship between infection and high levels of glucose in respiratory secretions. However, many questions remain about the role of glucose in bronchial secretions and a possible increased risk of infection.
Firstly, what is the mechanism by which high glucose levels occur in bronchial secretions? The very low concentration of glucose in normal respiratory airway surface fluid $(<0.5 \mathrm{mmol} / \mathrm{l})$ is thought to be actively maintained by reabsorption of glucose by an epithelial sodium glucose co-transporter. ${ }^{5}$ In a previous study increasing hyperglycaemia was associated with increasing glucose levels in respiratory secretions. ${ }^{6}$ All subjects with a blood glucose level of $>10.1 \mathrm{mmol} / \mathrm{l}$ had abnormal glucose levels in respiratory secretions. This suggests that at a threshold level of hyperglycaemia there is "overflow" into bronchial secretions, perhaps because active reabsorption of airways fluid glucose by sodium glucose co-transporters is saturated or inefficient in the presence of hyperglycaemia. In addition to "leakage" due to hyperglycaemia, glucose could also enter bronchial secretions via the breakdown of the integrity of endothelial and epithelial layers as a result of local or systemic inflammation. This possibility is supported by earlier work by Philips et $a l^{6}$ which found that non-diabetic subjects with acute viral rhinitis have abnormal levels of glucose in their respiratory tract secretions.

Secondly, is the association of abnormal glucose levels and infection in bronchial aspirates causally related? Rather than increasing the risk of infection, the association of MRSA with abnormal glucose levels in bronchial aspirates could reflect the effects of a third confounding factor. Alternatively, abnormal glucose levels in bronchial secretions could just be a marker for hyperglycaemia and it is the blood glucose level that affects susceptibility to respiratory infection. Corticosteroid therapy and illness severity are the two most obvious confounding factors that are known to influence the levels of infection and glucose, but neither was significantly different between patients with abnormal or normal glucose levels in bronchial aspirates. Diabetes could also be an independent risk factor for infection irrespective of hyperglycaemia, but in this study most of the patients had raised blood glucose levels due to stress hyperglycaemia rather than diabetes. Antibiotic use could also be increased in patients with hyperglycaemia and lead to higher levels of MRSA infection, but unfortunately data on antibiotics was not provided in the study by Philips et al. The proportion of patients with infiltrates on the chest radiograph and the $\mathrm{C}$ reactive protein level were both increased in patients with abnormal glucose levels in bronchial aspirates, ${ }^{2}$ and the authors have interpreted this as evidence for pneumonia due to MRSA in this group. However, this would give an implausibly high incidence of MRSA pneumonia in these patients. It is more likely that the pulmonary infiltrates in these patients had many different causes, and the presence of lung shadowing could be another possible confounding factor associated independently with abnormal glucose levels and increased infection in bronchial aspirates. Additional prospective detailed studies are required to evaluate in more detail the relationship between glucose levels and infection in bronchial aspirates before the association can be confirmed to be clinically important.

Laboratory studies suggest that it is biologically plausible that high glucose levels in bodily fluids can lead to an increased risk of infection. Glucose is an excellent source of nutrition for many bacteria, and it is also an environmental signal that can modulate bacterial gene expression and therefore potentially affect virulence. Furthermore, glucose can inhibit various aspects of the immune system including phagocyte and $\mathrm{T}$ cell function. ${ }^{7}$ However, these effects usually require much higher levels of glucose than those observed in bronchial secretions in this study. At present there are few data on the effects of glucose on physical lung defences such as mucociliary function, but the increased osmolality of airways fluid could adversely affect mucus clearance. Hyperglycaemia may also have a "hangover" effect on the function of migrating white cells, in which case abnormal glucose levels in the respiratory tract would be a markerbut not necessarily a cause-for impaired respiratory immunity.

The third question this article raises is whether abnormal glucose levels in bronchial aspirates is only associated with $S$ aureus infection, as the incidence of other pathogens was too low for any conclusions to be drawn. If respiratory host defences are impaired by abnormal levels of glucose, this would increase infection by other pathogens in addition to MRSA. In addition, many bacterial and fungal species, including the important respiratory tract pathogens Streptococcus pneumoniae, Pseudomonas aeruginosa, and 
Aspergillus fumigatus, can use glucose as a carbon source. Therefore, if abnormal glucose levels in respiratory secretions do lead to an increase in infection, the pathogens affected will probably not be limited to MRSA. This may have implications in controlling infection in other patient groups-for example, patients with cystic fibrosis who frequently have co-existent diabetes and chronic bronchial suppuration, or patients on long term corticosteroid treatment for chronic lung conditions such as pulmonary fibrosis and asthma.

The novel observation by Philips et $a l^{2}$ that MRSA infection is associated with abnormal glucose levels in respiratory tract secretions may eventually lead to improved control of MRSA and potentially other respiratory tract infections in high risk patients. However, further research is needed to evaluate the potential mechanisms underlying this observation to confirm whether abnormal glucose levels in respiratory secretions cause the increased risk of infection, and whether intervention to lower blood glucose levels will reduce the incidence of respiratory infection.

Thorax 2005;60:711-712.

doi: $10.1136 /$ thx.2005.044875

Correspondence to: Dr J S Brown, Centre for Respiratory Research, Department of Medicine, Royal Free and University College Medical School, Rayne Institute, London WCIE 6JJ, UK; jeremy.brown@ucl.ac.uk

\section{REFERENCES}

1 Fluit AC, Wielders CL, Verhoef J, et al. Epidemiology and susceptibility of 3051
Staphylococcus aureus isolates from 25 university hospitals participating in the European SENTRY study. J Clin Microbiol 2001;39:3727-32.

2 Philips BJ, Redman J, Brennen A, et al. Glucose in bronchial aspirates increases the risk of respiratory MRSA in intubated patients. Thorax 2005;60:761-4.

3 McAlister FA, Majumdar SR, Blitz S, et al. The relation between hyperglycemia and outcomes in 2471 patients admitted to the hospital with community-acquired pneumonia. Diabetes Care 2005;28:810-5

4 van den Berghe G, Wouters P, Weekers F, et al. Intensive insulin therapy in the critically ill patient. N Engl J Med 2001;345:1359-67.

5 Basset G, Saumon G, Bouchonnet F, et al. Apical sodium-sugar transport in pulmonary epithelium in situ. Biochim Biophys Acta 1988:942:1 1-8.

6 Philips BJ, Meguer JX, Redman J, et al. Factors determining the appearance of glucose in uppe and lower respiratory tract secretions. Intensive Care Med 2003;29:2204-10.

7 Saiki O, Negoro S, Tsuyuguchi I, et al. Depressed immunological defence mechanisms in mice with experimentally induced diabetes. Infect Immun 1980;28:127-31.

\section{Journal impact factors for 2004: another rise for Thorax}

\section{J A Wedzicha, S L Johnston, D M Mitchell}

\section{The impact factor for Thorax continues to rise}

$\mathrm{T}$ he journal impact factors for the year 2004 have recently been announced. The impact factor reflects the number of citations in 2004 to the number of original papers and reviews published in Thorax in 2002 and 2003. We are very pleased to let all our readers know that the impact factor for Thorax has risen from 4.188 in 2003 to 5.040 in 2004. Thorax is the second highest ranked respiratory journal in terms of impact factor, behind the American Journal of Respiratory and Critical Care Medicine. The impact factors for the main respiratory journals are listed in table 1.

The impact factor for Thorax has risen over the last few years and this reflects the high quality original papers and reviews we have received for publication. $^{12}$ In 2002 and 2003 we also published useful management guidelines for common conditions including the new British Thoracic Society (BTS)/ Scottish Intercollegiate Guidelines Network (SIGN) guidelines for the management of asthma in February $2003,{ }^{34}$ and BTS guidelines for the management of community acquired pneumonia in children, ${ }^{5}$ the use of
Table 1 Journal impact factors for 2004: respiratory journals

\begin{tabular}{ll}
\hline $\begin{array}{l}\text { American Journal of Respiratory } \\
\text { and Critical Care Medicine }\end{array}$ & 8.123 \\
$\begin{array}{l}\text { Thorax } \\
\text { American Journal of Respiratory }\end{array}$ & 5.040 \\
Cell and Molecular Biology & 4.175 \\
$\begin{array}{l}\text { American Journal of Physiology - } \\
\text { Lung Cellular and Molecular }\end{array}$ & 4.051 \\
$\begin{array}{l}\text { Pathology } \\
\text { Respiratory Research } \\
\text { Journal of Thoracic and }\end{array}$ & 4.028 \\
$\begin{array}{l}\text { Cardiovascular Surgery } \\
\text { Chest }\end{array}$ & 3.263 \\
$\begin{array}{l}\text { European Respiratory Journal } \\
\text { Journal of Heart and Lung }\end{array}$ & 3.118 \\
$\begin{array}{l}\text { Transplantation } \\
\text { Respiratory Medicine }\end{array}$ & 3.096 \\
& 2.813 \\
\hline
\end{tabular}

non-invasive ventilation in acute respiratory failure, ${ }^{6}$ guidelines on air travel, ${ }^{7}$ the management of pulmonary embolism, ${ }^{89}$ the management of pleural disease, ${ }^{10}$ and on respiratory aspects of fitness for diving. ${ }^{11}$

Over the past few years we have seen a marked rise in submissions to the journal, especially of high quality original papers, ${ }^{12}$ and we very much urge you to continue to send us your best papers. The increase in the impact factor reflects the success of the journal, and the future for Thorax is very good indeed.

Thorax 2005;60:712

doi: $10.1136 /$ thx.2005.050922

\section{Authors' affiliations}

J A Wedzicha, S L Johnston, D M Mitchell, Thorax Editorial Office

Correspondence to: Professor J A Wedzicha, Thorax Editorial Office, BMA House, Tavistock Square, London WClH 9JR, UK;

i.a.wedzicha@medsch.ucl.ac.uk

\section{REFERENCES}

1 Knox AJ, Britton J. Journal impact factors for 2000: Thorax flying yet higher. Thorax 2001;56:587.

2 Wedzicha JA, Johnston SL, Mitchell DM. Journal impact factors for 2003: Thorax increases. Thorax 2004;59:736.

3 BTS/SIGN. British guidelines on management of asthma. Thorax 2003;58(Suppl I):i1-94.

4 Higgins BG, Douglas JG. The new BTS/SIGN asthma guidelines: where evidence leads the way. Thorax 2003:58:98-9.

5 British Thoracic Society. Guidelines for the management of community acquired pneumonia in childhood. Thorax 2002;57(Suppl I):i1-24.

6 British Thoracic Society. Non-invasive ventilation in acute respiratory failure. Thorax 2002;57:192-211.

7 British Thoracic Society. Managing passengers with respiratory disease planning air travel: British Thoracic Society recommendations. Thorax 2002; 57:289-304.

8 British Thoracic Society. British Thoracic Society guidelines for the management of suspected acute pulmonary embolism. Thorax 2003;58:470-83.

9 Miller AC, Boldy DAR. Pulmonary embolism guidelines: will they work? Thorax 2003;58:463.

10 British Thoracic Society. BTS guidelines for management of pleural disease. Thorax 2003:58(Suppl II):ii 1-59.

11 British Thoracic Society. BTS guidelines on respiratory aspects of fitness for diving. Thorax 2003;58:3-13.

12 Wedzicha JA, Johnston SL, Mitchell DM. Annual report 2004. Thorax 2004;59:1015-7. 